\title{
Monitoring Chigger Mites for Orientia tsutsugamushi in Field Small Mammals in Hwaseong-si, Gyeonggi-do, Korea, 2019-2020
}

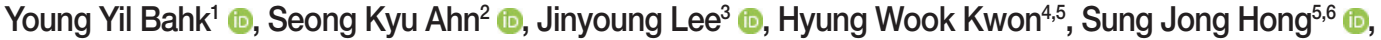 \\ Tong-Soo $\mathrm{Kim}^{3,5, *}$ (i) \\ ${ }^{1}$ Department of Biotechnology, College of Biomedical and Health Science, Konkuk University, Chungju 27478, Korea; ${ }^{2}$ Infectious Diseases \\ Investigation Division, Jeonnam Institute of Public Health and Environment, Muan 58568, Korea; ${ }^{3}$ Department of Parasitology and Tropical Medicine \\ \& Global Resource Bank of Parasitic Protozoa Pathogens, Inha University School of Medicine, Incheon 22212, Korea; ${ }^{4}$ Department of Life Sciences, \\ Incheon National University, Incheon 22012, Korea; ${ }^{5}$ Convergence Research Center for Insect Vectors, Incheon National University, Incheon 22012, \\ Korea; ${ }^{6}$ Department of Medical Environmental Biology, Chung-Ang University College of Medicine, Seoul 06974, Korea
}

\begin{abstract}
Incidence of tsutsugamushi disease (scrub typhus) caused by Orientia tsutsugamushi, is steadily increasing. It is a mite-borne disease transmitted by chigger mites. In this study, the chigger mites were collected from field small mammals in Hwaseong-si (city), Gyeonggi-do (province), Korea, 2019 and 2020. The field small mammals captured were 56 Apodemus agrarius (94.9\%) and 3 Crocidura lasiura (5.1\%). A total of 7,531 chigger mites were collected from the captured small mammals. Using PCR test, 153 chigger mite pools were examined and 17 pools were reported positive for O. tsutsugamushi. The O. tsutsugamushi were identified to 5 strains; Jecheon strain was most prevalent, followed by Boryong strain. The other strains were OI011, Taguchi, and Shimokoshi. Collectively, these results provide essential regional information on mite-borne tsutsugamushi disease in the Hwaseong-si, and further contribute to bring awareness and rapid diagnosis for the tsutsugamushi disease.
\end{abstract}

Key words: Orientia tsutsugamushi, chigger mite, small mammal, Hwaseong-si

Due to global climate change, there is a resurgence of vectorborne infectious diseases, and their potential to spread casualties among human populations has emerged as a significant burden on public health systems. Tsutsugamushi disease, also known as scrub typhus, has emerged as a critical public health issue over the years, spreading through the southern and eastern parts of Asia and the Pacific Rim including, but not limited to, Korea, Japan, China, India, Indonesia, Thailand, Sri Lanka and the Philippines [1]. Currently there is a widespread resurgence of the disease. This disease was the third most frequently diagnosed and reported infectious disease in Korea in 2012 [2], is caused by the obligate intracellular bacterium, Orientia tsutsugamushi (a Gram-negative a-proteobacterium of the Rickettsiaceae family), which is present in chigger mites (hosts belonging to the Leptotrombidium genus) and is transmitted to

\footnotetext{
- Received 3 May 2021, revised 3 June 2021, accepted 3 June 2021.

*Corresponding author (tongsookim@inha.ac.kr)

(C) 2021. Korean Society for Parasitology and Tropical Medicine

This is an Open Access article distributed under the terms of the Creative Commons

Attribution Non-Commercial License (https://creativecommons.org/licenses/by-nc/4.0) which permits unrestricted non-commercial use, distribution, and reproduction in any

medium, provided the original work is properly cited.
}

humans via bites [3]. The developmental cycle of chigger mites consists of the egg, larval (also called chigger) and adult stages. Because mites need vertebrate tissue fluid to transform from chiggers to pupae, they can potentially transmit pathogens to human and natural hosts. These causal agents are maintained in nature transovarially in chigger mites. Therefore, chigger mites serve as both the vector and the reservoir. The eradication of $O$. tsutsugamushi from its natural cycle with any available strategy is regarded as impossible [4]. Although hundreds of strains have been described, there are 5 definable clusters of O. tsutsugamushi as a human pathogen, i.e., Boryong/Kuroki, Saitama (including Youngworl strain), Karp-related (including Jecheon strain), Kawasaki, and JG-related (including Wonju strain), based on the nucleotide sequences of the $56 \mathrm{kDa}$ typespecific antigen gene $[5,6]$. Mites are arthropods that serve as vectors of tsutsugamushi disease and their endemicity is closely related to their habitation [7]. The clinical manifestations vary and are accompanied by severe complications caused by injuries to multiple organs [6]. Individuals bitten by mite vector may exhibit non-specific symptoms such as flu or eschar and rashes at the bite site of bite. General symptoms such as 
cough, lymphadenopathy, headache, nausea, fever and abdominal pain may also be present in the infected patients. During the acute phase of the disease, conjunctival hemorrhage is commonly observed. Ulcers and hemorrhages in the gastrointestinal tract are also observed in severely ill patients. In the absence of proper and timely treatment, the mean fatality rate can increase up to $70 \%$ [8]. It is clear that infection by O. tsutsugamushi may persist for a lifetime despite the antibiotic therapy. Currently, doxycycline is mainly used for treatment with high efficacy [9].

In Korea, tsutsugamushi disease was first identified among in British soldiers in 1951 during the Korean War and reemerged in the indigenous population in 1986 [10,11]. This disease is classified as a group 3 infectious disease according to the Korean Act on the Prevention and Control of Infectious Diseases. The annual number of reported cases has fluctuated significantly and, since 2001 and up to 2020, 125,189 patients with tsutsugamushi disease patients have been reported, thus highlighting this disease as a significant public health issue [12]. In 2019 to 2020, a total of 8,449 cases were diagnosed and reported (4,005 cases in 2019; 4,444 cases in 2020). The endemicity of tsutsugamushi disease is closely related to the habitation of chigger mites comprising 39 Leptotrombidium species carrying the pathogen O. tsutsugamushi found in Korea [13]. This disease is mainly transmitted by L. pallidum, L. scutellare, and L. palpale [14]. Although the most promising preventive measures is the development of an effectively protective vaccine, a vaccine against this disease is not available, and general protective measures merely include avoiding exposure, wearing appropriate clothing, and using repellents to prevent chigger mite bites [1]. Surveillance for prevalence estimation is one of the key methods in the study of the epidemiology of chigger mites and chigger mite-borne parasites. Moreover, determining the role of chigger mites as vectors and the infected proportion is vital for an adequate chigger mite control program. Chigger mites feed on small mammals to which they can transmit $O$. tsutsugamushi. Field small mammal species that are present in Korea and harbor chigger mites include Apodemus agrarius, Micromys minutus, Mus musculus, Crocidura lasiura, Microtus fortis, Rattus norvegicus and Eothernomys rufocanus [15]. It has been suggested that the absence of reported autochthonous cases in Korea from 1951 to 1985 and the rapid, steady increase in annual clinical cases may be attributed to global climate change [4].

In this study, we describe the species composition, abun- dance, and distribution of chigger mites and the detection of any tsutsugamushi disease pathogens carried by them in Hwaseong-si, Gyeonggi-do in 2019-2020 to monitor and reduce the potential for the autochthonous transmission of chigger mite-borne Rickettesiae. This study aimed to gather information related to the transmission of vector-borne diseases, especially tsutsugamushi disease, through long-term surveillance of pathogen vectors in the study region (central area of the Korean peninsula). In addition, field small mammals and their harbored ectoparasites were monitored to obtain information on the seasonal and geographic distribution of chigger mites. Our surveillance could provide a basis for future epidemiological studies and the risk evaluation of chigger miteborne pathogens.

Hwaseong-si is a city in Gyeonggi-do located in the western area of the Korean Peninsula and has the largest area of farmland in the province. The average annual temperature in this area is $11.5^{\circ} \mathrm{C}$, with an average rainfall of $1,259 \mathrm{~mm}$ per year. The climate classification of the Hwaseong-si area based on the Köpen-Geiger method is Dwa (Monsoon-influenced hotsummer humid continental climate) [16].

Field small mammals were captured in the Hwaseong-si area using Sherman live collapsible rodent traps at 5 locations (rice field (geographic index: 37.182406/126.903726), vegetable field (37.181603/126.900196), waterway (37.182490/126.904874), reservoir (37.189779/126.902948), and hill (37.181458/ 126.898072). A total of 100 traps per each location were equally distributed among the 5 locations within the study areas. The traps were set up each night and placed in a grid format every $10 \mathrm{~m}$ according to the land topology and were baited with a peanut butter applied to the cookies to attract the smell. The traps were collected in 3 months (April, October, and November) in the Hwaseong-si area. The captured field small mammals were transported alive to a laboratory in the Department of Parasitology and Tropical Medicine of Inha University and identified using taxonomic keys [17]. Following transfer to the laboratory, cervical dislocation was performed to kill the transferred field small mammals. The field small mammals were euthanized using $\mathrm{CO}_{2}$ in an enclosed space. Information about the field small mammals was recorded and they were then hung upside down for $72 \mathrm{hr}$ to collect the chigger mites; Petri dishes with distilled water were installed under the captured field small mammals to collect the mites and prevent their drying. After $72 \mathrm{hr}$, staffs in the laboratory gathered the fallen chigger mites using a sterile needle under an inverted 
microscope and recorded their abundance. A representative number was chosen from the total number of chigger mites recovered from the captured field small mammals.

The collected chigger mites were pooled (1-30/pool) according to the small mammal species, collection site, and time of collection. After mixing with PBS, the chigger mites were ground using a bead bitter. After transferred to microcentrifuge tubes at $4^{\circ} \mathrm{C}$, the homogenates were assayed for $O$. tsutsugamushi. To detect $O$. tsutsugamushi DNA, nested PCR were performed using INNOPLEX ${ }^{\mathrm{TM}}$ TSUTSU detection kit (iNtRON Biotechnology, Seoul, Korea) with DNA samples prepared using the G-Spin ${ }^{\mathrm{TM}}$ Total DNA Extraction Kit (iNtRON Biotechnology) in accordance with the manufacturer's instructions $[18,19]$. The primer pairs for the $56 \mathrm{kDa}$ strain-specific antigen gene of O. tsutsugamushi were WJ173 (forward) 5'-CCAG GATTTAGAGCAGAG-3', WJ174 (reverse) 5'-CGCTAGGTTT ATTAGCAT-3' (Amplicon size 509 bp), WJ175 (nested forward) 5'-CCTCAGCCTACTATRAKKCC-3' and WJ176 (nested reverse) 5'-AGCATTGATAAT-GCAGCAAG-ACC-3' (amplicon size 350 bp). After electrophoresed in 1.3\% agarose gel, the amplicon bands were cut out and used for DNA sequencing. The derived nucleotide sequences were analyzed for genotype using NCBIBLAST search.

A total of 59 field small mammals (29 in 2019; 30 in 2020) were captured for 3 months (April, October and November) with a collection rate $9.8 \%$ (59 field small mammals/600 Sherman ${ }^{\mathrm{TM}}$ live traps (collection rate: $9.8 \%, 9.7 \%$ in 2019; $10.0 \%$ in 2020) (Table 1). Two species of field small mammals were captured; one species Apodemus agrarius in 2019, 2 species in 2020. The striped field mouse (A. agrarius) accounted for $94.9 \%$ of the captured field small mammals, and the Ussuri white-toothed shrew (C. lasiura) (5.1\% (Table 2)). The most frequently captured site was the waterway (28.8\% field small mammals , 6 in 2019 and 11 in 2020), followed by the vegetable field (20.3\%, 8 in 2019 and 4 in 2020). At the remaining 3 sites (rice field, hill and reservoir), each 10 field small mammals were captured by the Sherman ${ }^{\mathrm{TM}}$ live traps (Table 3).

All 59 captured field small mammals were infested with ectoparasites. Almost all of them (93.2\%) were infected with chigger mites (Table 3; Supplementary Table S1). A total of 7,531 chigger mites (3,863 in 2019 and 3,668 in 2020) were collected from the captured field small mammals with a mean chigger mite index of 127.6 chigger mites per rodent (117.1 in 2019 and 141.1 in 2020). Field small mammals infested with chigger mites were found at all 5 collection areas during the entire studying period. A rodent (A. agrarius) captured in October 2020 was infected with the highest number of chigger mites throughout the surveyed period $(n=482,6.4 \%$ of the

Table 2. Species and collection rates of the field small mammals captured with Sherman ${ }^{\text {TM }}$ live traps in Hwaseong-si, 2019 and 2020

\begin{tabular}{|c|c|c|c|c|c|}
\hline \multirow[b]{2}{*}{ Year } & \multirow{2}{*}{$\begin{array}{l}\text { Collection } \\
\text { time (month) }\end{array}$} & \multirow{2}{*}{$\begin{array}{l}\text { No. of } \\
\text { traps }\end{array}$} & \multicolumn{2}{|c|}{ No. of captured hosts } & \multirow{2}{*}{$\begin{array}{c}\text { Subtotal } \\
(\%)\end{array}$} \\
\hline & & & $\begin{array}{c}\text { Apodemus } \\
\text { agrarius }\end{array}$ & $\begin{array}{c}\text { Crocidura } \\
\text { lasiura }\end{array}$ & \\
\hline \multirow[t]{4}{*}{2019} & April & 100 & 10 & 0 & $10(10.0)$ \\
\hline & October & 100 & 10 & 0 & $10(10.0)$ \\
\hline & November & 100 & 9 & 0 & $9(9.0)$ \\
\hline & Subtotal & 300 & 29 & 0 & $29(9.7)$ \\
\hline \multirow[t]{4}{*}{2020} & April & 100 & 6 & 0 & $6(6.0)$ \\
\hline & October & 100 & 8 & 1 & $9(9.0)$ \\
\hline & November & 100 & 13 & 2 & $15(15.0)$ \\
\hline & Subtotal & 300 & 27 & 3 & $30(10.0)$ \\
\hline Total & & 600 & 56 & 3 & $59(9.8)$ \\
\hline
\end{tabular}

Table 1. Collection rate of small mammal hosts and chigger mite index in Hwaseong-si, Korea, 2019 and 2020

\begin{tabular}{|c|c|c|c|c|c|c|c|c|c|}
\hline Year & $\begin{array}{l}\text { Collection } \\
\text { (month) }\end{array}$ & $\begin{array}{l}\text { No. of } \\
\text { traps }\end{array}$ & $\begin{array}{l}\text { No. of small } \\
\text { mammal- } \\
\text { captured } \\
\text { traps }\end{array}$ & $\begin{array}{l}\text { No. of chigger } \\
\text { mites }\end{array}$ & $\begin{array}{l}\text { Chigger mite } \\
\text { index }\end{array}$ & $\begin{array}{l}\text { No. of tested } \\
\text { chigger mites }\end{array}$ & $\begin{array}{c}\text { No. of tested } \\
\text { pools }\end{array}$ & $\begin{array}{l}\text { No. of positive } \\
\text { pools }\end{array}$ & $\mathrm{MPR}^{*}$ \\
\hline \multirow[t]{3}{*}{2019} & April & 100 & 10 & 1,202 & 120.2 & 599 & 27 & 1 & 0.17 \\
\hline & October & 100 & 10 & 383 & 38.3 & 194 & 12 & 2 & 1.00 \\
\hline & November & 100 & 13 & 2,278 & 175.2 & 1,144 & 42 & 8 & 0.70 \\
\hline \multirow[t]{4}{*}{2020} & April & 100 & 6 & 476 & 79.3 & 245 & 12 & 0 & 0 \\
\hline & October & 100 & 9 & 1,943 & 242.9 & 969 & 35 & 2 & 0.21 \\
\hline & November & 100 & 11 & 1,249 & 138.8 & 622 & 25 & 3 & 0.48 \\
\hline & Subtotal & 300 & 26 & 3,668 & 141.1 & 1,836 & 72 & 5 & 0.27 \\
\hline Total & & 600 & 59 & 7,531 & 127.6 & 3,773 & 153 & 16 & 0.42 \\
\hline
\end{tabular}

*MPR (Minimum positive rate), number of positive pool(s)/total number of the tested chigger mites $\times 100 \%$. 
Table 3. Collection rate of small mammal hosts and chigger mite index in Hwaseongsi in April, October, and November in 2019 and 2020

\begin{tabular}{|c|c|c|c|c|c|c|c|}
\hline Year & Site & Collectiontime & No. of traps & $\begin{array}{l}\text { No. of field small } \\
\text { mammals }\end{array}$ & $\begin{array}{c}\text { Collection rates } \\
(\%)\end{array}$ & $\begin{array}{l}\text { No. of chigger } \\
\text { mites }\end{array}$ & $\begin{array}{l}\text { Chigger mite } \\
\text { index }\end{array}$ \\
\hline \multirow[t]{21}{*}{2019} & \multirow[t]{4}{*}{ Rice field } & April & 20 & 3 & 15.0 & 326 & 108.7 \\
\hline & & October & 20 & 2 & 10.0 & 40 & 20.0 \\
\hline & & November & 20 & 2 & 10.0 & 415 & 207.5 \\
\hline & & Sub-total & 60 & 7 & 11.7 & 781 & 111.6 \\
\hline & \multirow[t]{4}{*}{ Vegetable field } & April & 20 & 2 & 10.0 & 400 & 200.0 \\
\hline & & October & 20 & 3 & 15.0 & 232 & 77.3 \\
\hline & & November & 20 & 3 & 15.0 & 371 & 123.7 \\
\hline & & Sub-total & 60 & 8 & 13.3 & 1,003 & 125.4 \\
\hline & \multirow[t]{4}{*}{ Waterway } & April & 20 & 2 & 10.0 & 226 & 113.0 \\
\hline & & October & 20 & 1 & 5.0 & 0 & 0 \\
\hline & & November & 20 & 3 & 15.0 & 599 & 199.7 \\
\hline & & Sub-total & 60 & 6 & 10.0 & 825 & 137.5 \\
\hline & \multirow[t]{4}{*}{ Hill } & April & 20 & 0 & 0 & 0 & 0 \\
\hline & & October & 20 & 3 & 15.0 & 111 & 37.0 \\
\hline & & November & 20 & 2 & 10.0 & 345 & 172.5 \\
\hline & & Sub-total & 60 & 5 & 8.3 & 456 & 91.2 \\
\hline & \multirow[t]{4}{*}{ Reservoir } & April & 20 & 3 & 15.0 & 250 & 83.3 \\
\hline & & October & 20 & 1 & 5.0 & 0 & 0 \\
\hline & & November & 20 & 3 & 15.0 & 548 & 182.7 \\
\hline & & Sub-total & 60 & 7 & 11.7 & 798 & 114.0 \\
\hline & Total & & 300 & 33 & 11.0 & 3,863 & 117.1 \\
\hline \multirow[t]{21}{*}{2020} & \multirow[t]{4}{*}{ Rice field } & April & 20 & 2 & 10.0 & 10 & 5.0 \\
\hline & & October & 20 & 1 & 5.0 & 412 & 412.0 \\
\hline & & November & 20 & 0 & 0 & 0 & 0 \\
\hline & & Sub-total & 60 & 3 & 5.0 & 422 & 140.7 \\
\hline & \multirow[t]{4}{*}{ Vegetable field } & April & 20 & 0 & 0 & 0 & 0 \\
\hline & & October & 20 & 1 & 5.0 & 350 & 350.0 \\
\hline & & November & 20 & 3 & 15.0 & 434 & 144.7 \\
\hline & & Sub-total & 60 & 4 & 6.7 & 784 & 196.0 \\
\hline & \multirow[t]{4}{*}{ Waterway } & April & 20 & 3 & 0.2 & 154 & 51.3 \\
\hline & & October & 20 & 6 & 30.0 & 998 & 166.3 \\
\hline & & November & 20 & 2 & 10.0 & 221 & 110.5 \\
\hline & & Sub-total & 60 & 11 & 18.3 & 1,373 & 124.8 \\
\hline & \multirow[t]{4}{*}{ Hill } & April & 20 & 1 & 5.0 & 312 & 312.0 \\
\hline & & October & 20 & 1 & 5.0 & 183 & 183.0 \\
\hline & & November & 20 & 3 & 15.0 & 311 & 103.7 \\
\hline & & Sub-total & 60 & 5 & 8.3 & 806 & 161.2 \\
\hline & \multirow[t]{4}{*}{ Reservoir } & April & 20 & 0 & 0 & 0 & 0 \\
\hline & & October & 20 & 0 & 0 & 0 & 0 \\
\hline & & November & 20 & 3 & 15.0 & 283 & 94.3 \\
\hline & & Sub-total & 60 & 3 & 5.0 & 283 & 94.3 \\
\hline & \multicolumn{2}{|l|}{ Total } & 300 & 26 & 8.7 & 3,668 & 141.1 \\
\hline Total & & & 600 & 59 & 9.8 & 7,531 & 127.6 \\
\hline
\end{tabular}

total collected chigger mites). Another rodent (A. agrarius) captured in October 2020 at the rice field had 412 chigger mites (5.4\% of the total). Of the 7,531 chigger mites, $99.8 \%$ were collected from A. agrarius, and 15 chigger mites (less than $0.5 \%$ ) were from $C$. lasiura. These results indicated that $A$. agrarius was the dominant rodent host species for the surveyed chigger mites in the Hwaseong-si area. This dominancy of A. agrarius was consistent with the previously reported findings $[18,19]$.

In this survey, a representative number of the chigger mites 
( $\mathrm{n}=3,773$, approximately $50 \%$ of the total collected chigger mites) were tested due to practical difficulties associated with examining all captured 7,531 chigger mites recovered from the captured field small mammals and the PCR experiments for the detection of for the 56-kDa type-specific antigen gene from O. tsutsugamushi (Supplementary Table S1). Successful amplification generated a 350 bp product. Of the 153 tested pools, 17 pools were positive for $O$. tsutsugamushi infection among the collected chigger mites recovered from the captured field small mammals. The minimum positive rate (MPR; number of positive pool(s)/total tested number of chigger mites $\times 100 \%$ ) was 0.42 (0.57 in 2019; 0.27 in 2020, respectively) (Table 1). The PCR amplicons obtained from the prepared gDNA of O. tsutsugamushi from the pooled chigger mite samples were sequenced. From the analysis of the derived nucleotide sequences for matching genotypes using the NCBI-BLAST service, 5 different $O$. tsutsugamushi strains were identified and the Jecheon strain was the most prevalent (8/17 positive pools (47.1\%); 6 in 2019; 2 in 2020, respectively), followed by the Boryong strain (2/17 positive pools (11.8\%); both in 2019). The other strains from the pooled samples were OI011, Taguchi, and Shimokoshi, respectively (Supplementary Table S1). Our research group previously monitored the same locations for 4 years from 2015 [18,19]. A total of 171 field small mammals were captured at the same location in the same months (April, October, and November), a total of 7,531 ectoparasitic chigger mites were recovered from the captured field small mammals, and a total of 3,773 collected chigger mites were subjected to PCR for the amplification of O. tsutsugamushi DNA. However, of the examined chigger mites, none of them tested positive for O. tsutsugamushi. From 2001 to 2020, the total number of patients with tsutsugamushi disease patients reported in Hwaseong-si was 2,749, accounting for 2.2\% of the patients nationwide $(2,749 / 125,189$ cases nationwide, 2,749 / 10,876 total number of cases in Gyeonggi-do (25.3\%)) of patients nationwide. The total number of cases in 2019 and 2020 was 61 . The number of patients is decreasing compared with the numbers in previous years; however, considering our survey results, it is necessary to strengthen and maintain an onsite monitoring system for the chigger mites. Hwaseong-si in Gyeonggi-do is a city adjacent to Chungcheongnam province, one of the provinces with a high prevalence of tsutsugamushi disease in Korea $(13,982 / 125,198$ cases in 2001 to 2020, $11.2 \%)$. It is necessary to actively cope with changes in the occurrence of vector-borne diseases including tsutsugamushi dis- ease, which may be related to environmental conditions such as the geographic impacts and the global climate change.

This study aimed to achieve a more comprehensive understanding of tsutsugamushi disease transmitted by chigger mites on wild rodent in the Hwaseong-si area, by investigating the chigger mites as the vector of tsutsugamushi disease recovered from the host species and their status of infection by $O$. tsutsugamushi. Improved surveillance of the distribution of vectors and reservoir hosts and a better understanding of the potential impact of climate change have led to the recognition of previously neglected bacteria as serious pathogens. In addition, human population growth, globalization, and increased travel have contributed to the emergence of new pathogens and changing patterns of infectious disease. Therefore, further studies must continue to analyze the spread of vector-borne diseases. Thus, long-term monitoring of infectious disease pathogens, vectors, and hosts, as conducted in our 6-year surveillance, is pivotal to address the public health burden.

\section{ACKNOWLEDGMENTS}

This study was supported by the Korean Disease Control and Prevention Agency (4851-304-320), the Priority Research Centers Program through the National Research Foundation funded by the Ministry of Education (2020R1A6A1A03041954) and the Inha University Research Fund (65321-1) in Korea.

\section{CONFLICT OF INTEREST}

The authors declare that there is no conflict of interest regarding the publication of this article.

\section{REFERENCES}

1. Xu G, Walker DH, Jupiter D, Melby PC, Arcari CM. A review of the global epidemiology of scrub typhus. PLoS Negl Trop Dis 2017; 11: e0006062. https://doi.org/10.1371/journal.pntd.0006062

2. Ro HJ, Lee H, Park EC, Lee CS, Il Kim S, Jun S. Ultrastructural visualization of Orientia tsutsugamushi in biopsied eschars and monocytes from scrub typhus patients in South Korea. Sci Rep 2018; 8: 17373. https://doi.org/10.1038/s41598-018-35775-9

3. Paris DH, Shelite TR, Day NP, Walker DH. Unsolved problems related to scrub typhus: a seriously neglected life-threatening disease. Am J Negl Trop Dis 2013; 89: 301-307. https://doi.org/10. 4269/ajtmh.13-0064

4. Walker DH. Scrub typhus-Scientific neglect, ever-widening impact. N Engl J Med 2016; 375: 913-915. https://doi.org/10.1056/ 
NEJMp1608499

5. Choi YJ, Lee IY, Song HJ, Kim J, Park HJ, Song D, Jang WJ. Geographical distribution of Orientia tsutsugamushi strains in chiggers from three provinces in Korea. Microbiol Immunol 2018; 62: 547-553. https://doi.org/10.1111/1348-0421.12639

6. Kelly DJ, Fuerst PA, Ching WM, Richards AL. Scrub typhus: the geographic distribution of phenotypic and genotypic variants of Orientia tsutsugamushi. Clin Infect Dis 2009; 48: S203-230. https://doi.org/10.1086/596576

7. Banerjee A, Kulkarni S. Orientia tsutsugamushi: the dangerous yet neglected foe from the East. Int J Med Microbiol 2021; 311: 151467. https://doi.org/10.1016/j.ijmm.2020.151467

8. Bonell A, Lebell Y, Newton PN, Crump JA, Paris DH. Estimating the burden of scrub typhus: a systematic review. PLoS Negl Trop Dis 2017; 11: e0005838. https://doi.org/10.1371/journal.pntd.0005838

9. Kim MS, Baek JH, Lee JS, Chung MH, Lee SM, Kang JS. High in vitro infectivity of a doxycycline-insensitive strain of Orientia tsutsugamushi. Infect Chemother 2013; 45: 431-434. https://doi.org/10.3947/ ic.2013.45.4.431

10. Munro-Faure AD, Andrew R, Missen GA, Mackay-Dick J. Scrub typhus in Korea. J R Army Med Corps 1951; 97: 227-229. https:// pubmed.ncbi.nlm.nih.gov/14889509/

11. Chung MH, Kang JS. History of tsutsugamushi disease in Korea. Infect Chemother 2019; 51: 196-209. https://doi.org/10.3947/ ic.2019.51.2.196

12. Korean Centers for Disease Control and Prevention (KCDC). Disease Web Statistics System [Internet]. Available from: http:// www.kdca.go.kr/npt/biz/npp/nppMain.do

13. Ree HI, Lee IY, Cho MK. Determination of the vector species of tsutsugamushi diseases in Korea. Korean J Parasitol 1991; 29: 87-92. https://doi.org/10.3347/kjp.1991.29.1.87

14. Jackson EB, Danauskas JX, Smadel JE, Fuller HS, Coale MC, Bozeman FM. Occurrence of Rickettsia tsutsugamushi in Korean field small mammals and chiggers. Am J Hyg 1957; 66: 309-320. https://doi.org/10.1093/oxfordjournals.aje.a119904

15. Ree HI, Cho MK, Lee IY, Jeon SH. Comparative epidemiological studies on vector/reservoir animals of tsutsugamushi disease between high and low endemic areas in Korea. Korean J Parasitol 1995; 33: 27-36. http://dx.doi.org/10.3347/kjp.1995.33.1.27

16. Kottek M, Grieser J, Beck C, Rudolf B, Rubel F. World map of the Köppen-Geiger climate classification updated. Meteorologische Zeitschrift 2006; 15: 259-263. https://doi.org/10.1127/09412948/2006/0130

17. PH Won. Illustrated Encyclopedia of Fauna \& Flora of Korea, Vol. 7 Mammals. Ministry of Education, Seoul, Korea. Ministry of Education. 1967, pp 185-255 (in Korean).

18. Jun H, Jegal S, Kim-Jeon MD, Roh JY, Lee WG, Park SH, Ahn SK, Lee J, Gong YW, Kwon MJ, Bahk YY, Kim TS. Three-year surveillance (2016-2018) of chigger mite vector for tsutsugamushi disease in the Hwaseong-Si area of Gyeonggi-Do Republic of Korea. Entomol Res 2020; 50: 63-73. https://doi.org/10.1111/17485967.12403

19. Bahk YY, Jun H, Park SH, Jung H, Jegal S, Kim-Jeon MD, Roh, JY, Lee WG, Ahn SK, Lee J, Joo K, Gong YW, Kwon MJ, Kim TS. Surveillance of chigger mite vectors for tsutsugamushi disease in the Hwaseong Area, Gyeonggi-do, Republic of Korea, 2015. Korean J Parasitol 2020; 58: 301-308. https://doi.org/10.3347/kjp.2020. 58.3.301 